\title{
Limitations of Cyclosporin A Inhibition of the Permeability Transition in CNS Mitochondria
}

\author{
Nickolay Brustovetsky and Janet M. Dubinsky \\ Department of Neuroscience, University of Minnesota, Minneapolis, Minnesota 55455
}

\begin{abstract}
Activation of the mitochondrial permeability transition may contribute to excitotoxic neuronal death (Ankarcrona et al., 1996; Dubinsky and Levi, 1998). However, cyclosporin A (CsA), a potent inhibitor of the permeability transition in liver mitochondria, only protects against neuronal injury by limited doses of glutamate and selected ischemic paradigms. The lack of consistent CsA inhibition of the mitochondrial permeability transition was analyzed with the use of isolated brain mitochondria. Changes in the permeability of the inner mitochondrial membrane were evaluated by monitoring mitochondrial membrane potential $(\Delta \psi)$, using the distribution of tetraphenylphosphonium, and by monitoring mitochondrial swelling, using light absorbance measurements. Metabolic impairments, large $\mathrm{Ca}^{2+}$ loads, omission of external $\mathrm{Mg}^{2+}$, or low doses of palmitic acid or the protonophore FCCP exacerbated $\mathrm{Ca}^{2+}$-induced sustained depolarizations and swelling and eliminated CsA inhibition. BSA restored CsA inhibi-
\end{abstract}

tion in mitochondria challenged with $50 \mu \mathrm{M} \mathrm{Ca}{ }^{2+}$, but not with $100 \mu \mathrm{M} \mathrm{Ca}{ }^{2+}$. CsA failed to prevent $\mathrm{Ca}^{2+}$-induced depolarization or to repolarize mitochondria when mitochondria were depolarized excessively. Similarly, CsA failed to prevent mitochondrial swelling or PEG-induced shrinkage after swelling when the $\mathrm{Ca}^{2+}$ challenge produced a strong, sustained depolarization. Thus in brain mitochondria CsA may be effective only as an inhibitor of the permeability transition and the $\mathrm{Ca}^{2+}$-activated low permeability state under conditions of partial depolarization. In contrast, ADP plus oligomycin inhibited both permeabilities under all of the conditions that were tested. In situ, the neuroprotective action of CsA may be limited to glutamate challenges sufficiently toxic to induce the permeability transition but not so severe that mitochondrial depolarization exceeds threshold.

Key words: permeability transition; cyclosporin A; excitotoxicity; mitochondria; neurodegeneration; cyclophilin
Under high calcium loads or oxidative stress a proteinaceous structure in the inner mitochondrial membrane produces a mitochondrial permeability transition (mPT). Functional properties of the $\mathrm{mPT}$ have been studied extensively in liver and heart mitochondria (Bernardi et al., 1994; Zoratti and Szabo, 1995), but only recently has the mPT been characterized in neuronal tissue (Kristal and Dubinsky, 1997; Andreyev et al., 1998; Dubinsky and Levi, 1998; Brustovetsky and Dubinsky, 2000). We recently have delineated conditions distinguishing both low and high permeability states of $\mathrm{mPT}$ operation in brain mitochondria (Brustovetsky and Dubinsky, 2000).

CsA is considered to be a potent inhibitor of the $\mathrm{mPT}$ as compared with ADP and $\mathrm{Mg}^{2+}$, the next most effective protective agents (Fournier et al., 1987; Crompton et al., 1988; Broekemeier et al., 1989; Zoratti and Szabo, 1995). By interacting with a mitochondrial cyclophilin, CsA may inhibit the mPT by preventing cyclophilin association with the adenine nucleotide translocator or other structure comprising the $\mathrm{mPT}$ pore (Halestrap and Davidson, 1990; Nicolli et al., 1996). In liver and heart mitochondria CsA protection depends on the magnitude of mitochondrial $\mathrm{Ca}^{2+}$ loading (Bernardi et al., 1992) and the presence of external $\mathrm{Mg}^{2+}$ (Novgorodov et al., 1994). Accumulation of free fatty acids (FFA) accompanying $\mathrm{mPT}$ induction by $\mathrm{Ca}^{2+}$ plus oxidants, but not by $\mathrm{Ca}^{2+}$ plus phosphate, prevents $\mathrm{mPT}$ closure by $\mathrm{CsA}$ in liver mitochondria (Broekemeier and Pfeiffer, 1995). In heart mitochondria CsA and ADP act synergistically to inhibit the mPT. The loss

Received March 13, 2000; revised Aug. 11, 2000; accepted Aug. 24, 2000.

This work was supported by the Huntington's Disease Society of America and National Institute on Aging Grant AG10034 to J.M.D. and by American Heart Association Fellowship (Minnesota Affiliate) $9804691 X$ to N.B. We thank Carter Herman for preparation of the hippocampal cultures and execution of the toxicity experiments and Dr. Vincent Barnett for the use of his spectrophotometer. Dr. G. Engel and V. Widmer of Sandoz Pharmaceuticals kindly provided the CsA.

Correspondence should be addressed to Dr. Janet M. Dubinsky, Departments of Neuroscience and Physiology, University of Minnesota Medical School, 6-145 Jackson Hall, 321 Church Street SE, Minneapolis, MN 55455. E-mail: dubin001@tc.umn.edu. Dr. Brustovetsky's permanent address: Institute of Theoretical and Experimental Biophysics, Russian Academy of Science, Pushchino 142292, Moscow Region, Russia. Copyright (C) 2000 Society for Neuroscience $0270-6474 / 00 / 208229-09 \$ 15.00 / 0$ of endogenous adenine nucleotides accompanying the $\mathrm{mPT}$ pore opening may explain the decreased effectiveness of CsA inhibition (Novgorodov et al., 1992).

CsA has been used to identify activation of the mPT as a crucial factor leading to cell death (Zamzami et al., 1996). The mPT remains closed during cardiac ischemia but opens on reperfusion, causing mitochondrial dysfunction (Griffiths and Halestrap, 1995). The mPT contributes to the lethal injury of hepatocytes exposed to tert-butylhydroperoxide (Nieminen et al., 1995). In brain, with abundant cyclophilin, CsA protection has been reported only for hypoglycemia or ischemic insults in hyper- or hypoglycemic animals (Folbergrova et al., 1997; Li et al., 1997; Friberg et al., 1998). Although CsA neuroprotection has been attributed to calcineurin inhibition (Dawson et al., 1993; Ankarcrona et al., 1996), CsA ameliorates mitochondrial depolarization, suggesting mPT participation in excitotoxicity (Nieminen et al., 1996; Schinder et al., 1996; White and Reynolds, 1996; Vergun et al., 1999), yet the extent of CsA neuroprotection has been limited and varies substantially for the doses that have been tested to date.

The balance between modulators of the mPT, $\mathrm{Ca}^{2+}, \mathrm{Mg}^{2+}$, FFA, and adenine nucleotides may vary in brain cells in situ, determining the relative vulnerability to injury and the extent of possible CsA protection. We therefore tested CsA against a range of glutamate challenges. We investigated the effects of these modulators on CsA inhibition of both high and low permeability states of the $\mathrm{mPT}$ in isolated brain mitochondria. We found that the extent of mitochondrial depolarization was associated with the ability of CsA to prevent opening and to close the mPT pore, limiting the effectiveness of CsA as a neuroprotective agent.

\section{MATERIALS AND METHODS}

Isolation of brain mitochondria. Brain mitochondria were isolated as previously reported (Brustovetsky and Dubinsky, 2000). For measurement of mitochondrial swelling the brain mitochondria were purified further on a discontinuous Percoll gradient to remove synaptosomes (Kristal and Dubinsky, 1997; Brustovetsky and Dubinsky, 2000).

Measurements of $\Delta \psi$, mitochondrial swelling, and respiration. Isolated brain mitochondrial experiments were performed in a medium containing (in mM) 215 mannitol, 50 sucrose, $3 \mathrm{KH}_{2} \mathrm{PO}_{4}$, and 10 HEPES, $\mathrm{pH} 7.4,320$ 
mOsm and the indicated amount of substrate at $30^{\circ} \mathrm{C}$ in a stirred $2.0 \mathrm{ml}$ chamber. $\mathrm{MgCl}_{2}(0.5 \mathrm{mM})$ was present unless indicated otherwise. Sucros$\mathrm{e}$-mannitol medium was used in preference to $\mathrm{KCl}$-based medium to prevent contributions from $\mathrm{K}^{+}$channel activation to mitochondrial potential and volume (Garlid, 1996). Although KCl medium would depolarize synaptosomes, $\mathrm{K}^{+}$-stimulated synaptosomal $\mathrm{Ca}^{2+}$ uptake also would diminish our applied calcium challenges by an unspecified amount (Blaustein, 1975). In preliminary experiments the purified brain mitochondria slowly lost accumulated tetraphenylphosphonium $\left(\mathrm{TPP}^{+}\right)$in $\mathrm{KCl}$ medium, whereas mitochondria in sucrose-mannitol-based medium maintained stable $\mathrm{TPP}^{+}$accumulations in excess of $30 \mathrm{~min}$. Because properties of liver mitochondria were altered after Percoll purification (Litsky and Pfeiffer, 1997) in experiments monitoring $\Delta \psi$ alone, unpurified mitochondria were used. Protein concentration in the chamber was $1.0-1.5 \mathrm{mg} / \mathrm{ml}$ or $0.1-0.2 \mathrm{mg} / \mathrm{ml}$ for unpurified or Percoll gradient-purified mitochondria, respectively, as determined by the Bradford method (Bradford, 1976). $\Delta \psi$ was followed with a TPP ${ }^{+}$-sensitive electrode (Kamo et al., 1979; Brustovetsky and Dubinsky, 2000). For the unpurified mitochondria the amount of TPP ${ }^{+}$distributed into synaptosomes was determined by comparing the initial $\left[\mathrm{TPP}^{+}\right]_{\mathrm{o}}$ in sucrose-mannitol medium $(0.41 \pm 0.03 \mu \mathrm{M}$, mean \pm SEM; $n=4$ ) with that in an identical medium containing $3 \mathrm{~mm}$ succinate plus $3 \mathrm{~mm}$ glutamate, with $125 \mathrm{~mm} \mathrm{KCl}$ substituted for the sucrose and mannitol $(0.52 \pm 0.02 \mu \mathrm{M} ; n=5)$ for the addition of equal volumes of the same mitochondrial preparation.

$\mathrm{Ca}^{2+}$-induced mitochondrial swelling, reflecting the opening of a large permeability pathway of the mPT, was followed spectrophotometrically $(540 \mathrm{~nm})$ at room temperature with a Beckman DU7500 spectrophotometer (Brustovetsky and Dubinsky, 2000). For simultaneous measurements the mitochondria were incubated at $30^{\circ} \mathrm{C}$ in a continuously stirred $0.3 \mathrm{ml}$ chamber equipped with both a miniature $\mathrm{TPP}^{+}$electrode and a photodiode light detector in combination with a laser light source $(670 \mathrm{~nm}$; Andreyev and Fiskum, 1999) through a light guide. Previous absorbance measurements that were made by scanning $300-800 \mathrm{~nm}$ wavelengths yielded no differences in responses at the different wavelengths (Kristal and Dubinsky, 1997). For each of these last measurements purified mitochondria were used because mitochondrial swelling was masked in the presence of synaptosomes. All data traces are representative of at least three replicates.

Oxygen consumption was measured with a miniature Clark-type electrode in a closed chamber, simultaneous with TPP ${ }^{+}$measurements, as previously described (Brustovetsky and Dubinsky, 2000).

Neuronal culture and toxicity experiments. Toxicity experiments were performed on hippocampal cultures $12-15 \mathrm{~d}$ in vitro, prepared from postnatal day 1 rat pups according to established laboratory procedures ( $\mathrm{Du}$ binsky, 1993). Briefly, cultures were exposed to glutamate in the range $10-500 \mu \mathrm{M}$ for $5 \mathrm{~min}$ in serum-free supplemented MEM, rinsed in Earle's basic salt solution, and incubated for $24 \mathrm{hr}$ before assessment of survival with the use of trypan blue exclusion, as previously described (Dubinsky, 1993). Where indicated, the cultures were pretreated with $1 \mu \mathrm{M} \mathrm{CsA}$ for 1 $\mathrm{hr}$ in addition to the continuous presence of CsA during the $24 \mathrm{hr}$ incubation period. Equal amounts of vehicle were present in all untreated controls.

\section{RESULTS}

\section{CsA effects on glutamate excitotoxicity}

In our experiments $1 \mu \mathrm{M}$ CsA partially protected neurons against $500 \mu \mathrm{M}$ glutamate but failed to protect neurons against injury induced by glutamate exposure over the entire range of glutamate concentrations that were tested (Fig. 1). Although CsA appeared to shift the average log $\mathrm{ED}_{50}$ of the glutamate dose-response curve to higher concentrations, this failed to reach significance with continued repetitions $\left[\log \mathrm{ED}_{50}\right.$ of $-3.50 \pm 0.22(n=5) 315 \mu \mathrm{M}$ for glutamate plus CsA vs $-3.83 \pm 0.19(n=4) 150 \mu \mathrm{M}$ for glutamate alone; $p=0.052$, two-tailed $t$ test]. Hill slopes were equally variable and not significantly different $(-1.5 \pm 0.6$ for glutamate vs $-1.3 \pm$ 0.5 for glutamate plus CsA). If only the cultures that were treated with $500 \mu \mathrm{M}$ glutamate were compared, however, a significant difference would be detected [18.9 $\pm 1.6 \%$ survival $(n=39)$ from 14 experiments for glutamate alone vs $41.3 \pm 1.7 \%$ survival $(n=$ 47) from 15 experiments for glutamate plus CsA; $p<0.0001$, two-tailed $t$ test]. In agreement with published reports (McDonald et al., 1996, 1997), higher CsA concentrations were themselves toxic and therefore did not protect against glutamate exposure. The inability of CsA to protect neurons across a broad range of glutamate concentrations could be interpreted to mean that the $\mathrm{mPT}$ is not involved in excitotoxicity. Alternately, these data could reflect the possibility that CsA is not an effective across-the-board inhibitor of the $\mathrm{mPT}$.

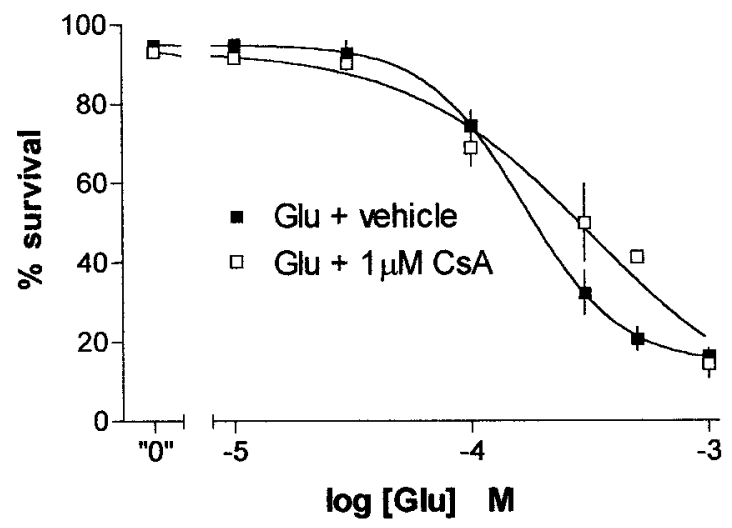

Figure 1. Dose dependence of glutamate-induced neuronal death in the absence and presence of $1 \mu \mathrm{M}$ CsA. Data from two representative experiments are shown. $\log \mathrm{ED}_{50}, \mathrm{ED}_{50}$ concentration in $\mu \mathrm{M}$, and Hill slopes for the glutamate $(\mathrm{Glu})$ and Glu plus CsA curves are $-3.78,166 \mu \mathrm{M}$, and -2.1 and $-3.49,321 \mu \mathrm{M}$, and -1.1 , respectively. Data represent the mean \pm SEM of three replicates at each point.

\section{Characterization of the $\mathrm{MPT}$ in isolated CNS mitochondria}

A high permeability pathway in the inner mitochondrial membrane, the $\mathrm{mPT}$, has been well characterized in liver mitochondria (Hunter and Haworth, 1979a-c). The first indication of mPT pore substates with a low permeability in liver mitochondria came from a comparison of the time courses for the transmembrane equilibration of small solutes after rapid pore opening (Pfeiffer et al., 1978). The low permeability pathway has a low conductance and is selective for small ions (Riley and Pfeiffer, 1985; Al-Nasser and Crompton, 1986; Broekemeier and Pfeiffer, 1995; Broekemeier et al., 1998).

CNS mitochondria respond to $\mathrm{Ca}^{2+}$ by the activation of both high and low permeability pathways in the inner mitochondrial membrane (Brustovetsky and Dubinsky, 2000). In 3 mm succinate $\mathrm{Ca}^{2+}$ activates a low permeability pathway that can be observed as a sustained depolarization without mitochondrial swelling (Brustovetsky and Dubinsky, 2000). In $3 \mathrm{~mm}$ succinate plus $3 \mathrm{~mm}$ glutamate $\mathrm{Ca}^{2+}$ produces a transient mitochondrial depolarization, rapid repolarization accompanied by calcium uptake, and a slowly progressive secondary depolarization and loss of accumulated $\mathrm{Ca}^{2+}$ accompanied by swelling (Dubinsky et al., 1999; Brustovetsky and Dubinsky, 2000). This later response characterizes the opening of the high permeability, classical mPT pathway (Brustovetsky and Dubinsky, 2000). In an intermediate substrate environment (10 mM succinate) a combination of both responses may be evident. The time course and amplitude of mitochondrial swelling also depend on the substrate environment (Fig. 2A). However, the maximal $\mathrm{Ca}^{2+}$-induced swelling amounted to approximately one-half of that seen in response to the addition of a nonspecific artificial channel former, alamethecin (Fig. 2B). The decreases in light scattering in response to $\mathrm{Ca}^{2+}$ representing mitochondrial swelling were reversed when mitochondria were incubated in isoosmotic medium containing high-molecular-weight polyethylene glycol (PEG; Fig. 3). Under these conditions PEG prevented swelling presumably by plugging the pore (Pfeiffer et al., 1995), and $\mathrm{Ca}^{2+}$-induced depolarization, possibly associated with the low permeability pathway, was observed (Fig. $3 B$ ). Simultaneously, the substantial activation of respiration by $\mathrm{Ca}^{2+}$ was not altered by PEG. The observed light scattering increase may reflect hydroxyapatite formation (Andreyev et al., 1998). In the absence of exogenous substrates the increase in light scattering was diminished (Fig. 4A). This condition was unlikely to be associated with appreciable $\mathrm{Ca}^{2+}$ influx. The size of the $\mathrm{Ca}^{2+}$-activated high permeability pore of brain mitochondria was estimated by using differently sized PEG molecules (Fig. 4A; Pfeiffer et al., 1995). As the molecular weight (MW) of the PEG increased, the amplitude of 


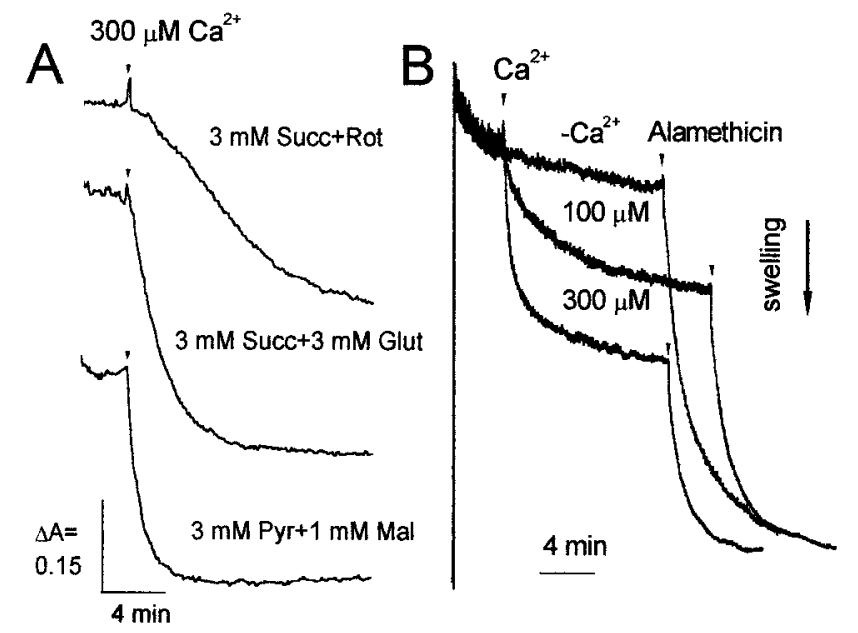

Figure 2. The kinetics and amplitude of mitochondrial swelling varied, depending on the magnitude of the $\mathrm{Ca}^{2+}$ load $(B)$ and the substrates available for mitochondrial respiration $(A)$. Alamethecin $(30 \mu \mathrm{g} / \mathrm{ml})$ was added in $B$ (arrows) to induce maximal swelling of the entire mitochondrial population.

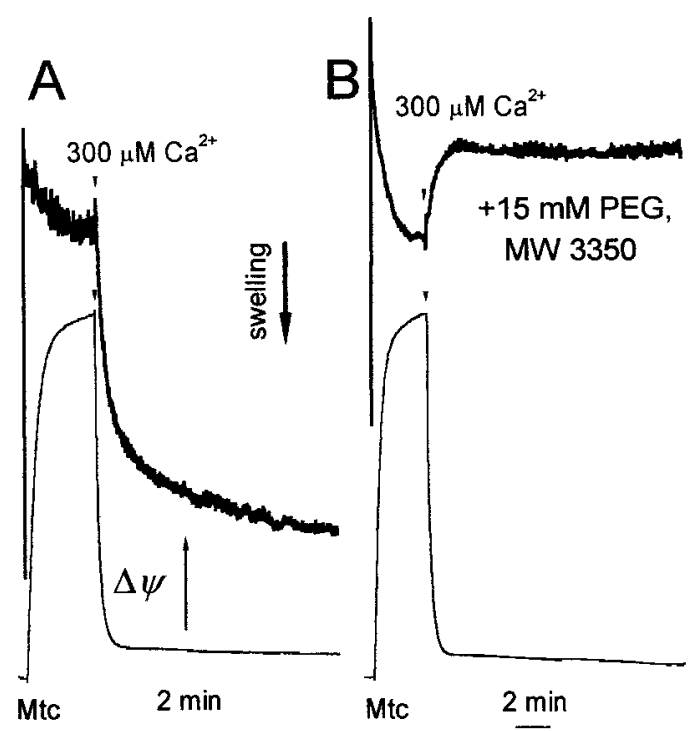

Figure 3. High-molecular-weight PEG prevented the light scattering decrease, but not the depolarization, produced by $\mathrm{Ca}^{2+}$. Mitochondrial swelling (light scattering, top trace) and membrane potential $\left(\mathrm{TPP}^{+}\right.$electrode response, bottom trace) were measured simultaneously in the presence $(B)$ or absence $(A)$ of PEG (MW 3350). A, Mitochondria were tested in the standard medium while respiring on $3 \mathrm{~mm}$ succinate plus $3 \mathrm{~mm}$ glutamate, $310 \mathrm{mOsm}$. $B$, Mitochondria were tested in a medium consisting of (in mM) 108 mannitol, 25 sucrose, 15 PEG (3350 MW), $10 \mathrm{KCl}, 10 \mathrm{HEPES}, 3$ $\mathrm{KH}_{2} \mathrm{PO}_{4}, 0.5 \mathrm{MgCl}_{2}, 3$ succinate, and 3 glutamate, $\mathrm{pH} 7.4,310 \mathrm{mOsm}$.

swelling decreased. Molecules of $1090 \mathrm{MW}$ would correspond to $50 \%$ inhibition of the high permeability $\mathrm{mPT}$ of brain mitochondria (Fig. $4 B$ ). The high permeability $\mathrm{mPT}$ was closed with the chelation of $\mathrm{Ca}^{2+}$ by EGTA. High-molecular-weight PEG addition after $\mathrm{Ca}^{2+}$-induced mitochondrial swelling had reached a steady state caused mitochondrial shrinkage (Fig. 5A). EGTA addition before PEG prevented the shrinkage, indicating that chelation of $\mathrm{Ca}^{2+}$ allowed the high permeability $\mathrm{mPT}$ to close and prevented mannitol-sucrose efflux (Fig. 5B; Haworth and Hunter, 1979).

\section{CsA effects on the $\mathrm{Ca}^{2+}$-activated low permeability pathway}

Mitochondria were examined for the ability of CsA to prevent opening or promote closure of both low and high permeability pathways. $\mathrm{TPP}^{+}$electrode measurements of mitochondrial mem-

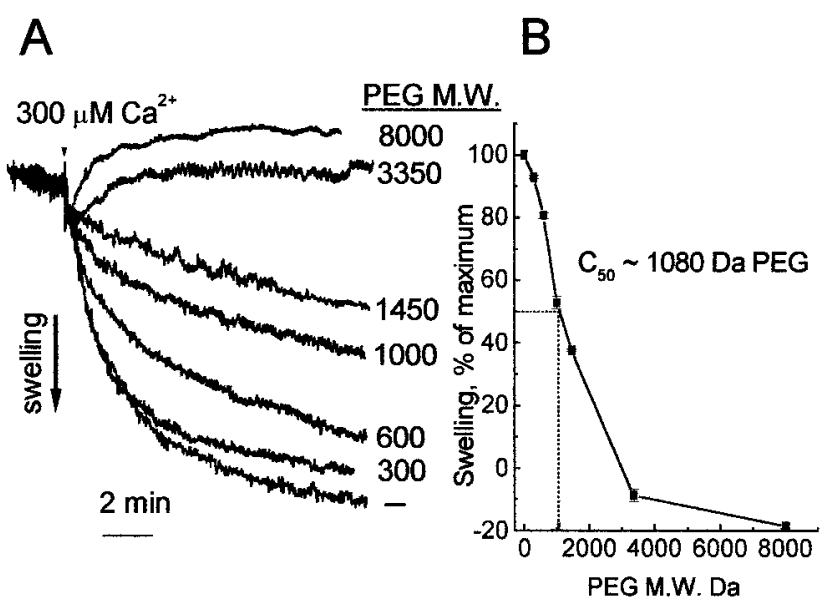

Figure 4. Sizing of the brain $\mathrm{mPT}$ pore by different molecular weight PEGs. $A, \mathrm{Ca}^{2+}$-activated decreases in light scattering traces were prevented progressively in the presence of PEGs of increasing molecular weights. Stock 300 mOsm solutions of the following PEG concentrations were made in standard medium without any sucrose or mannitol: PEG300, $227 \mathrm{mM}$; PEG600, 167 mM; PEG1000, 118 mM; PEG1450, 87 mM; PEG3350, 45 mM; PEG8000, 20.4 mM. Of each stock $30 \%$ was combined with $70 \%$ of the standard mannitol-sucrose medium to produce the solutions that were used in this experiment (Pfeiffer et al., 1995). The measurements were extended beyond the time period shown in $A$ until swelling reached the maximum value. $B$, Mitochondrial swelling, expressed as a percentage of the maximum observed in the absence of PEG, varied with PEG size. Half-maximal swelling corresponded to a MW of 1090 .

A

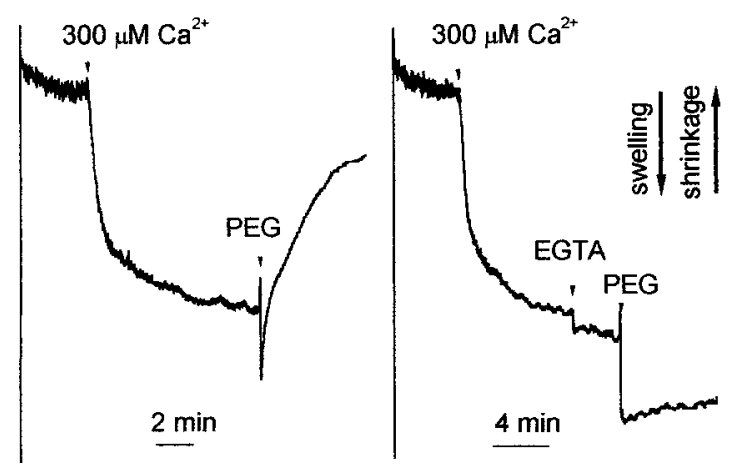

Figure 5. EGTA closed the brain mPT pore. $A$, Light scattering decreases in response to $\mathrm{Ca}^{2+}$ were reversed by the addition of PEG $(3350 \mathrm{MW}) . B$, The addition of $1.5 \mathrm{~mm}$ EGTA before PEG prevented PEG-induced mitochondrial shrinkage after steady-state pore opening by $\mathrm{Ca}^{2+}$. In both $A$ and $B$, mitochondria were respiring on $3 \mathrm{~mm}$ succinate plus $3 \mathrm{~mm}$ glutamate. PEG $(6.67 \%)$ was added to the standard testing medium for a final osmolarity of 395 mOsm.

brane potential were used to determine the ability of CsA to close the $\mathrm{Ca}^{2+}$-activated low permeability pathway. The addition of 50 $\mu \mathrm{M} \mathrm{Ca}^{2+}$ to mitochondria induced a sustained depolarization (Fig. 6 ), characteristic of the low permeability pathway (Brustovetsky and Dubinsky, 2000). CsA restored $\Delta \psi$, indicating an involvement of the $\mathrm{mPT}$ in the $\mathrm{Ca}^{2+}$-induced depolarization. However, CsA failed to restore $\Delta \psi$ after the stronger depolarization induced by $100 \mu \mathrm{M} \mathrm{Ca}^{2+}$, even at concentrations up to $6 \mu \mathrm{M}$. Added after CsA, ADP plus oligomycin, an inhibitor of $\mathrm{F}_{1} \mathrm{~F}_{0} \mathrm{ATP}$ synthase, repolarized mitochondria. ADP plus oligomycin also repolarized mitochondria in the absence of CsA (Brustovetsky and Dubinsky, 2000). The ADP-induced repolarization was interpreted to represent closure of the low permeability pathway that was activated here (Brustovetsky and Dubinsky, 2000). Omission of $\mathrm{Mg}^{2+}$ from the incubation medium exacerbated the $\mathrm{Ca}^{2+}$-induced depolarization and prevented CsA repolarization. The subsequent addition of $0.5 \mathrm{mM} \mathrm{Mg}^{2+}$ produced an insignificant repolarization, but ADP plus oligomycin nevertheless repolarized mitochondria rapidly. 


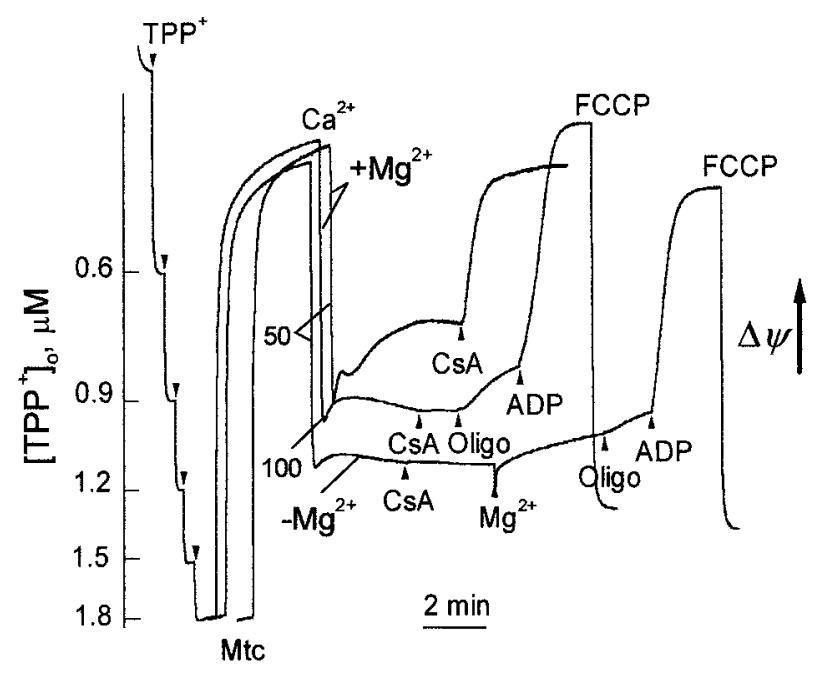

Figure 6. Dependence of the $\mathrm{Ca}^{2+}$-induced depolarization of isolated, unpurified brain mitochondria on the amount of added $\mathrm{Ca}^{2+}$ and on the presence of $\mathrm{Mg}^{2+}$. Initial repeated addition of $0.3 \mu \mathrm{M} \mathrm{TPP}{ }^{+}$determined the calibrations for TPP ${ }^{+}$electrode measurements of $\Delta \psi \cdot \mathrm{Ca}^{2+}(50$ or 100 $\mu \mathrm{M}$ ) was added to mitochondria (Mtc) as indicated by the number near each trace. Repolarization was induced by $1 \mu \mathrm{M} \mathrm{CsA}$ and $100 \mu \mathrm{M}$ ADP plus $1 \mu \mathrm{M}$ oligomycin (Oligo). In Figures 2-5 and 7, unpurified mitochondria were respiring on $3 \mathrm{~mm}$ succinate.

Under these experimental conditions the $\mathrm{Ca}^{2+}$ addition produced only a transient increase in respiration [Brustovetsky and Dubinsky (2000), their Fig. 4], followed by a slight decrease in steady-state oxygen consumption for $50 \mu \mathrm{M} \mathrm{Ca}^{2+}$ and no change for $100 \mu \mathrm{M} \mathrm{Ca}^{2+}$ (Table 1). The ability of CsA alone or in combination with ADP and oligomycin to repolarize mitochondria was not correlated with consistent changes in respiration. Specifically, increased respiratory rates were not responsible for repolarizing $\Delta \psi$.

In liver mitochondria a number of substances modulate the ability of CsA to prevent classic mPT induction, including $\mathrm{Mg}^{2+}$ and FFA (Novgorodov et al., 1994; Broekemeier and Pfeiffer, 1995). To test whether endogenous FFA could suppress CsA inhibition of the $\mathrm{mPT}$ in brain mitochondria, we used BSA to bind FFA in $\mathrm{Mg}^{2+}$-free medium (Bjorntorp et al., 1964). $\mathrm{Mg}^{2+}$ was removed from the medium because $\mathrm{Mg}^{2+}$ also can bind FFA (Shinohara et al., 1995). In the presence of BSA the $\mathrm{Ca}^{2+}$-induced depolarization was weaker (Fig. 7). In these conditions, despite the absence of external $\mathrm{Mg}^{2+}$, CsA repolarized mitochondria. Without BSA the CsA was ineffective. BSA alone did not repolarize mitochondria significantly. BSA, added after CsA, induced repolarization. CsA, added after BSA, also increased $\Delta \psi$. Thus the binding of FFA by BSA facilitated closure of the low permeability pathway by CsA. However, when $100 \mu \mathrm{M} \mathrm{Ca}{ }^{2+}$ depolarized mitochondria, CsA failed to repolarize mitochondria despite the presence of BSA (data not shown). The lack of CsA inhibition after high $\mathrm{Ca}^{2+}$ challenges might be explained by an accumulation of endogenous FFA because of the activation of mitochondrial $\mathrm{Ca}^{2+}$-dependent phospholipase $\mathrm{A}_{2}\left(\mathrm{PLA}_{2}\right.$; Waite et al., 1969; De Winter et al., 1984). Trifluoperazine $(100 \mu \mathrm{M})$, an inhibitor of mitochondrial

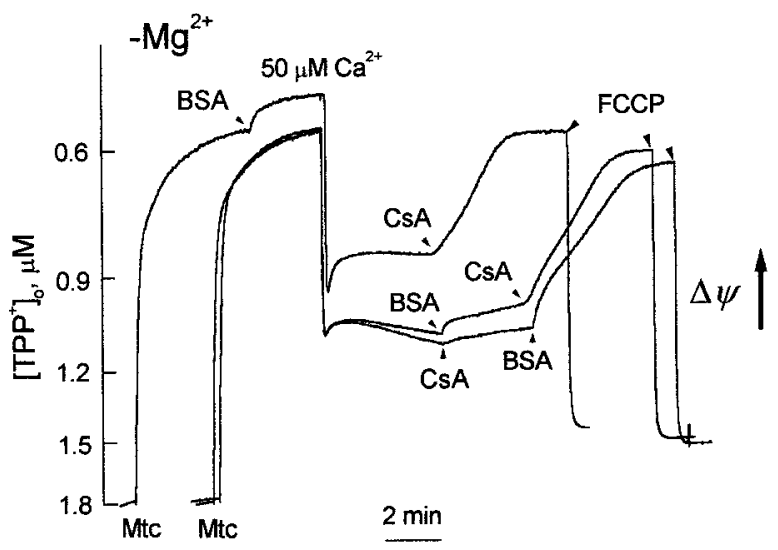

Figure 7. Restoration of CsA repolarization with the removal of FFA with $0.05 \%$ BSA. Shown are measurements of $\Delta \psi$ with a TPP ${ }^{+}$electrode in unpurified mitochondria respiring on $3 \mathrm{~mm}$ succinate in the absence of added $\mathrm{Mg}^{2+}$. Additions: $50 \mu \mathrm{M} \mathrm{Ca}^{2+}, 1 \mu \mathrm{M} \mathrm{CsA}$, and $1 \mu \mathrm{M}$ FCCP.

$\mathrm{PLA}_{2}$ from liver (Broekemeier et al., 1985), did not alter CsA efficiency. However, because the ability of trifluoperazine to inhibit $\mathrm{PLA}_{2}$ in brain mitochondria is unknown, this result does not rule out modulation of the low permeability pathway by FFA. Indeed, the addition of $20 \mu \mathrm{M}$ palmitate exacerbated $\mathrm{Ca}^{2+}$-induced depolarization and suppressed CsA repolarization (Fig. 8A). Palmitate itself induced negligible depolarization. ADP plus oligomycin, added after CsA, repolarized mitochondria. The addition of $0.05 \%$ BSA after CsA also repolarized mitochondria (data not shown). Thus both exogenous palmitate and endogenous FFA impeded the closure of the low permeability pathway by CsA.

$\mathrm{CsA}$ failed to close the $\mathrm{Ca}^{2+}$-induced low permeability pathway in the absence of $\mathrm{Mg}^{2+}$ or in the presence of FFA (Figs. 6-8). In all of these experiments depolarization was greater than in the experiments in which CsA successfully repolarized mitochondria. These results suggest that $\mathrm{CsA}$ inhibition may be related to the extent of depolarization. CsA might not be expected to have any effect if $\Delta \psi$ fell below some threshold. To test this hypothesis, we pretreated mitochondria with a low concentration of carbonyl cyanide $p$-(trifluoromethoxy)phenyl hydrazone (FCCP) that itself did not cause significant depolarization (Fig. $8 B$ ). After FCCP, $50 \mu \mathrm{M}$ $\mathrm{Ca}^{2+}$ produced a greater depolarization and CsA did not repolarize mitochondria. Thus the stronger the depolarization, the lower the probability that CsA would repolarize mitochondria.

To determine the degree of depolarization that was necessary to prevent CsA-induced closure of the low permeability pathway, we performed a series of experiments similar to those in Figures 6-8. The degree of depolarization was varied systematically by applying different concentrations of $\mathrm{Ca}^{2+}$ or by varying the concentrations of $\mathrm{Mg}^{2+}$, palmitate, or FCCP applied before a fixed $50 \mu \mathrm{M} \mathrm{Ca}^{2+}$ pulse. The sensitivity of the low permeability pathway to CsA correlated with the amplitude of depolarization regardless of the experimental manipulation (Fig. 9). CsA inhibition could not be detected if mitochondria were depolarized below an amount represented by $0.83 \mu \mathrm{M} \mathrm{TPP}{ }^{+}{ }_{\mathrm{o}}$. This threshold value should be considered as an estimate and may vary under different experimental

Table 1. Steady-state respiration rates for mitochondria in mannitol/sucrose medium with $0.5 \mathrm{mM} \mathrm{MgCl}_{2}$ and $3 \mathrm{~mm}$ succinate

\begin{tabular}{lllll}
{$\left[\mathrm{Ca}^{2+}\right]$} & Initial & $\mathrm{Ca}^{2+}$ & $1 \mu \mathrm{M} \mathrm{CsA}$ & $100 \mu \mathrm{M}$ ADP \\
\hline $50 \mu \mathrm{M}$ & $9.78 \pm 0.11(3)^{*}$ & $8.18 \pm 0.25(3)$ & $6.86 \pm 0.51(3)$ & $7.60 \pm 0.59(3)$ \\
$100 \mu \mathrm{M}$ & $9.00 \pm 1.09(5)$ & $8.30 \pm 0.82(5)$ & $9.12 \pm 0.22(3)$ & $9.19 \pm 0.85(5)$
\end{tabular}

Rates are nanomoles $\mathrm{O}_{2} / \mathrm{min} / \mathrm{mg}$ of protein [mean \pm SEM $(n)$ ] for 2-4 min initially or after the sequentially indicated additions. Oligomycin $(1 \mu \mathrm{M})$ was added before the ADP.

$* p<0.05$ compared to after additions, one-way ANOVA followed by Newman-Keuls Multiple Comparison test. A one-way ANOVA for respiration rates in the second row was not significant. 


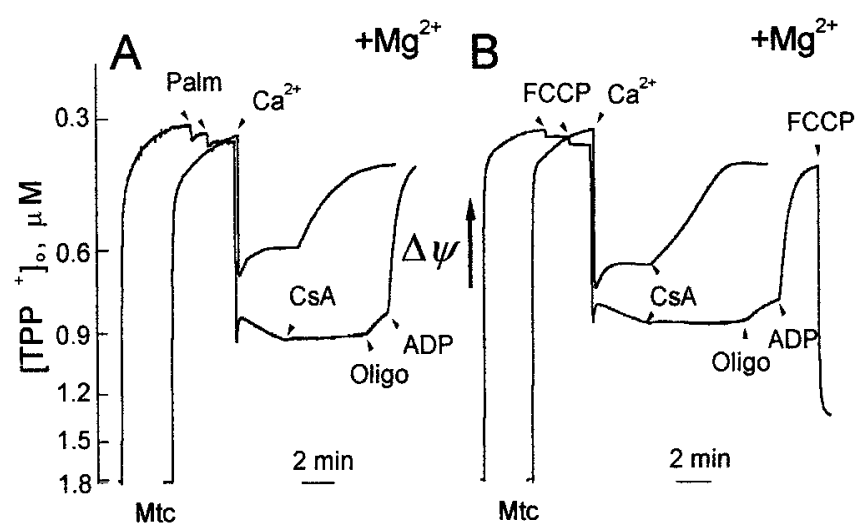

Figure 8. Palmitic acid and FCCP exacerbated $\mathrm{Ca}^{2+}$-induced depolarization and prevented the restoration of $\Delta \psi$ by CsA. $\mathrm{TPP}^{+}$electrode measurements were made in unpurified mitochondria in the presence of $3 \mathrm{~mm}$ succinate and $0.5 \mathrm{~mm}$ external $\mathrm{Mg}^{2+}$. Palmitic acid $(10 \mu \mathrm{M} ;$ Palm; $A)$ or 10 nM FCCP $(B)$ was added twice before $\mathrm{Ca}^{2+}$. Other additions: $50 \mu \mathrm{M} \mathrm{Ca}{ }^{2+}$, $1 \mu \mathrm{M} \mathrm{CsA}, 1 \mu \mathrm{M}$ oligomycin, $100 \mu \mathrm{M}$ ADP, and $1 \mu \mathrm{M}$ FCCP.

conditions. As an example of this variation, the threshold for CsA in repolarizing purified brain mitochondria appears to center between the 1.2 and $1.5 \mu \mathrm{M}$ level of $\mathrm{TPP}^{+}$accumulation (Fig. 10). The inability of $\mathrm{CsA}$ to repolarize mitochondria fully in this experiment may be attributable to lingering deleterious effects of the Percoll purification (Litsky and Pfeiffer, 1997). Thus under all conditions the ability of CsA to repolarize mitochondria appeared to be correlated inversely with the degree of mitochondrial depolarization.

To determine the ability of CsA to prevent the opening of the low permeability pathway, we added CsA before mitochondria (Fig. 11). We previously reported that CsA pretreatment was not sufficient to prevent $100 \mu \mathrm{M} \mathrm{Ca}{ }^{2+}$ from activating a sustained depolarization in CNS mitochondria respiring on $3 \mathrm{~mm}$ succinate (Brustovetsky and Dubinsky, 2000). However, CsA was able to prevent the sustained depolarization associated with a $50 \mu \mathrm{M}$ challenge (Fig. 11A). If a small amount of FCCP was added before $\mathrm{Ca}^{2+}$, the strength of the depolarization was increased and CsA became ineffective (Fig. 11B). Thus the ability of CsA to prevent

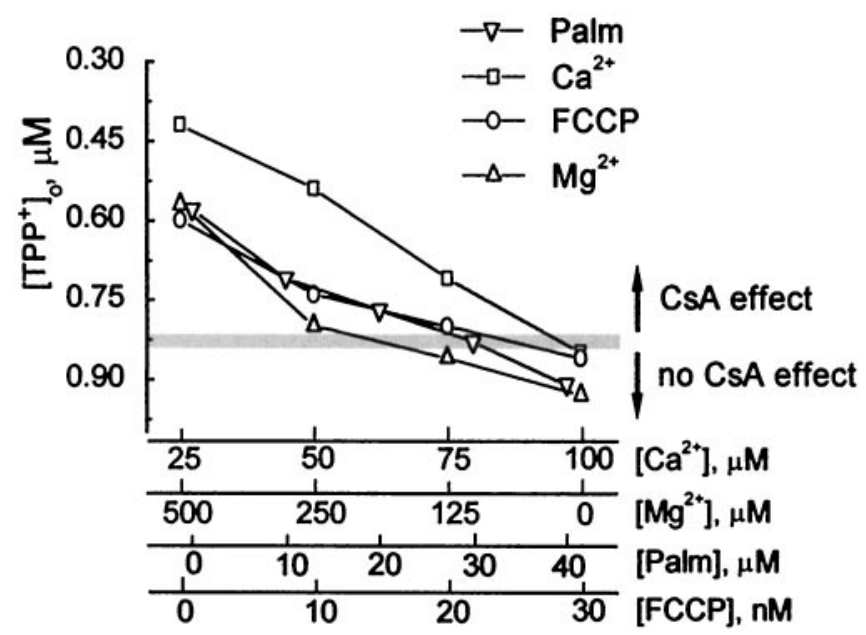

Figure 9. Determination of threshold for $\mathrm{CsA}$ repolarization in unpurified mitochondria. CsA was unable to repolarize mitochondria when mitochondria were depolarized beyond the value represented by $0.82 \mu \mathrm{M}$ external $\mathrm{TPP}^{+}$, independent of the treatment conditions. Depolarization amplitude was varied by increasing the added $\mathrm{Ca}^{2+}$ in the presence of $0.5 \mathrm{mM} \mathrm{Mg}{ }^{2+}$, by decreasing the $\mathrm{Mg}^{2+}$ concentration for a fixed $50 \mu \mathrm{M} \mathrm{Ca}^{2+}$ challenge, or by pretreating mitochondria with palmitic acid (Palm) or FCCP for a fixed $50 \mu \mathrm{M} \mathrm{Ca}^{2+}$ challenge in the presence of $0.5 \mathrm{mM} \mathrm{Mg}^{2+}$. [TPP $\mathrm{TP}_{\mathrm{o}}$ was measured $1 \mathrm{~min}$ after $\mathrm{Ca}^{2+}$ application.

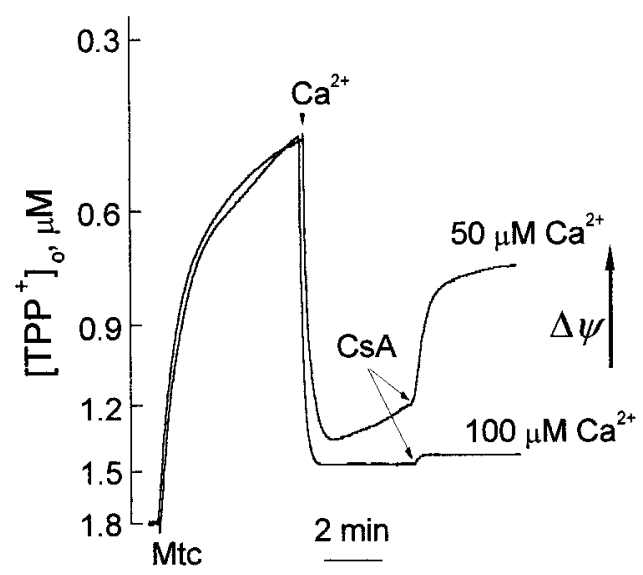

Figure 10. Repolarization of purified mitochondria by CsA correlated with the extent of depolarization induced by different $\mathrm{Ca}^{2+}$ pulses comparable to that observed for unpurified mitochondria (see Figs. 2-5). The indicated concentrations of $\mathrm{Ca}^{2+}$ and $1 \mu \mathrm{M}$ CsA were added at the arrows to mitochondria respiring on $3 \mathrm{~mm}$ succinate in the presence of $0.5 \mathrm{~mm} \mathrm{Mg}^{2+}$.

opening of the low permeability pathway again correlated with a drop of $\Delta \psi$.

\section{CsA effects on the MPT high permeability state}

$\mathrm{Ca}^{2+}$-induced changes in light absorbance of the CNS mitochondrial suspension were monitored to evaluate the protective action of $\mathrm{CsA}$ on the classic high permeability $\mathrm{mPT}$ pore (Fig. 12). Decreased absorbances corresponded to mitochondrial swelling (Dubinsky et al., 1999), and the amplitude of swelling increased with increasing $\mathrm{Ca}^{2+}$ doses (Kristal and Dubinsky, 1997). In the presence of $10 \mathrm{~mm}$ succinate CsA added before $\mathrm{Ca}^{2+}$ fully prevented swelling that was induced by $50 \mu \mathrm{M} \mathrm{Ca}{ }^{2+}$ even in the absence of external $\mathrm{Mg}^{2+}$ (Fig. 12A) but failed to protect against $100 \mu \mathrm{M} \mathrm{Ca}^{2+}$ despite the presence of $\mathrm{Mg}^{2+}$ (Fig. 12B). In contrast, ADP plus oligomycin suppressed swelling that was induced by 100 $\mu \mathrm{M} \mathrm{Ca}^{2+}$ (Fig. 12B). Moreover, when added after $100 \mu \mathrm{M} \mathrm{Ca}{ }^{2+}$, ADP inhibited the process of swelling (Fig. 12C) whereas CsA did not (Fig. 12B). Thus in vitro CsA exhibited limited protection against the opening of the high permeability state of the mPT pore, similar to its limited ability to close the low permeability pathway or to prevent glutamate toxicity.

To investigate the possible causes of CsA failure, we performed simultaneous measurements of mitochondrial swelling and $\Delta \psi$. In the presence of $10 \mathrm{~mm}$ succinate $100 \mu \mathrm{M} \mathrm{Ca}^{2+}$-induced mitochondrial swelling was accompanied by a deep, sustained depolarization

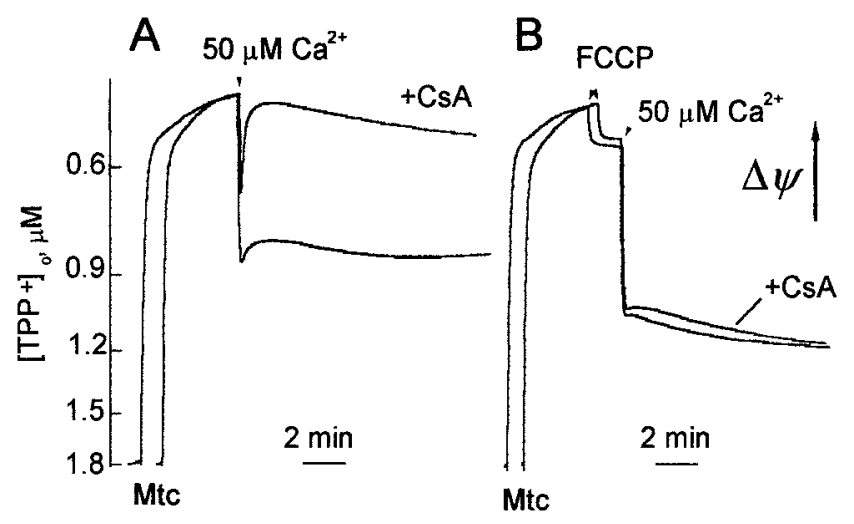

Figure 11. CsA prevention of activation of the low permeability pathway was associated with the degree of mitochondrial depolarization. In the indicated traces $1 \mu \mathrm{M}$ CsA was added before unpurified mitochondria in the presence of $3 \mathrm{~mm}$ succinate and $0.5 \mathrm{~mm} \mathrm{Mg}^{2+}$. In $B, 10 \mathrm{nM}$ FCCP addition produced only a minor depolarization itself but augmented the depolarization after $50 \mu \mathrm{M} \mathrm{Ca}{ }^{2+}$, nullifying the ability of CsA to prevent a sustained depolarization. 


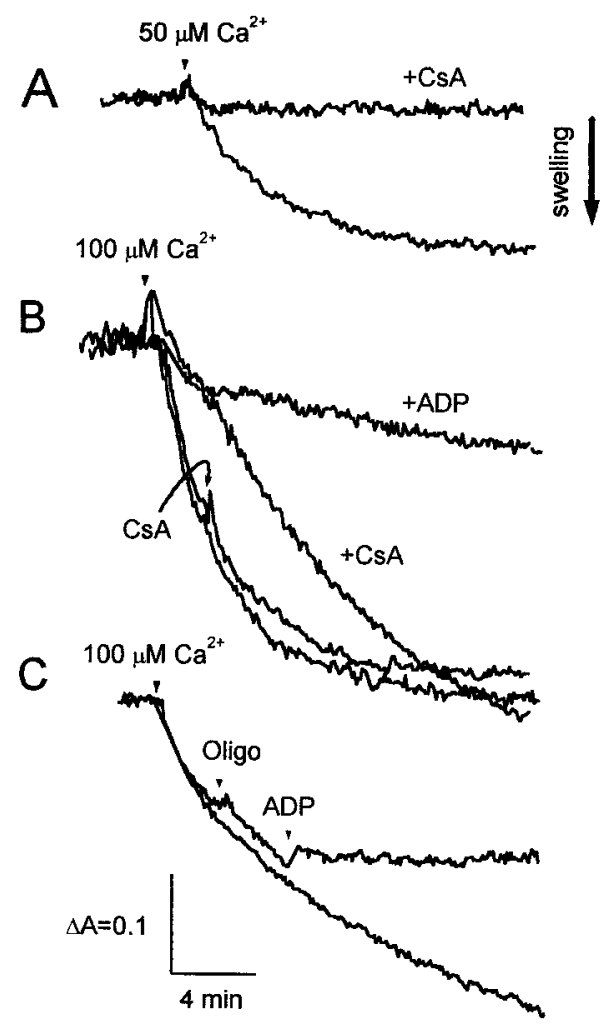

Figure 12. $\mathrm{Ca}^{2+}$-induced swelling of purified brain mitochondria. Protection by $\mathrm{CsA}$ depended on the amount of added $\mathrm{Ca}^{2+}$. ADP plus oligomycin inhibited the swelling induced by high $\mathrm{Ca}^{2+}$. Arrows mark the addition of 50 $\mu \mathrm{M} \mathrm{Ca}{ }^{2+}(A), 100 \mu \mathrm{M} \mathrm{Ca}{ }^{2+}(B, C), 1 \mu \mathrm{M} \mathrm{CsA}(B)$, and $1 \mu \mathrm{M}$ oligomycin and $100 \mu \mathrm{M}$ ADP $(C)$. Otherwise, $1 \mu \mathrm{M}$ CsA and/or $100 \mu \mathrm{M}$ ADP plus $1 \mu \mathrm{M}$ oligomycin were present in the medium before the mitochondrial addition to labeled traces. Oligomycin itself did not influence mitochondrial swelling. The incubation medium contained $10 \mathrm{~mm}$ succinate and, in $B$ and $C, 0.5$ $\mathrm{mM} \mathrm{MgCl}_{2}$. Scale bar in $C$ applies to the entire figure.

(Fig. 13A). Neither swelling nor depolarization was prevented by 1 $\mu \mathrm{M}$ CsA (Fig. 13B). In the presence of $3 \mathrm{~mm}$ succinate plus $3 \mathrm{~mm}$ glutamate $100 \mu \mathrm{M} \mathrm{Ca}{ }^{2+}$-induced mitochondrial swelling was accompanied by a transient depolarization, followed by a partial recovery of $\Delta \psi$ (Fig. 13C). In this case CsA both improved the recovery of $\Delta \psi$ and completely prevented swelling despite the same amount of added $\mathrm{Ca}^{2+}$ (Fig. 13D). The presence of glutamate improved mitochondrial energetics, preventing the oxaloacetate inhibition of succinate dehydrogenase, and enabled respiration to partially compensate the $\mathrm{Ca}^{2+}$-induced changes (Brustovetsky and Dubinsky, 2000). Increasing the $\mathrm{Ca}^{2+}$ concentration in this richer medium produced larger amplitude swelling and complete sustained depolarization, and CsA again became ineffective (Fig. $13 E, F)$. Similar results were achieved in purified mitochondria incubated in media with $125 \mathrm{~mm} \mathrm{KCl}$ substituted for the sucrosemannitol (our unpublished observations). Thus CsA prevention of the $\mathrm{mPT}$ opening may have been limited to conditions in which mitochondria were not depolarized severely, comparable to the limits on CsA action on the low permeability pathway.

To test this hypothesis further, we studied the influence of various $\mathrm{mPT}$ modulators on the $\mathrm{CsA}$ action. In the presence of succinate plus glutamate $3.3 \mu \mathrm{M}$ palmitate caused only a minor depolarization (Fig. 14A). $\mathrm{Ca}^{2+}(100 \mu \mathrm{M})$ added after palmitate induced a completely sustained depolarization accompanied by large amplitude swelling (compare Fig. $14 A$ with $C$ ). In these conditions CsA was ineffective (Fig. 14B). Similar results were obtained after pretreatment of mitochondria with 16.7 nM FCCP (Fig. $14 C, D)$. Omission of $\mathrm{Mg}^{2+}$ from the incubation medium also resulted in a $\mathrm{Ca}^{2+}$-induced sustained depolarization and prevented CsA inhibition of the mPT pore opening (Fig. 14E,F). In all five cases-in the limited substrate environment, after palmitate or

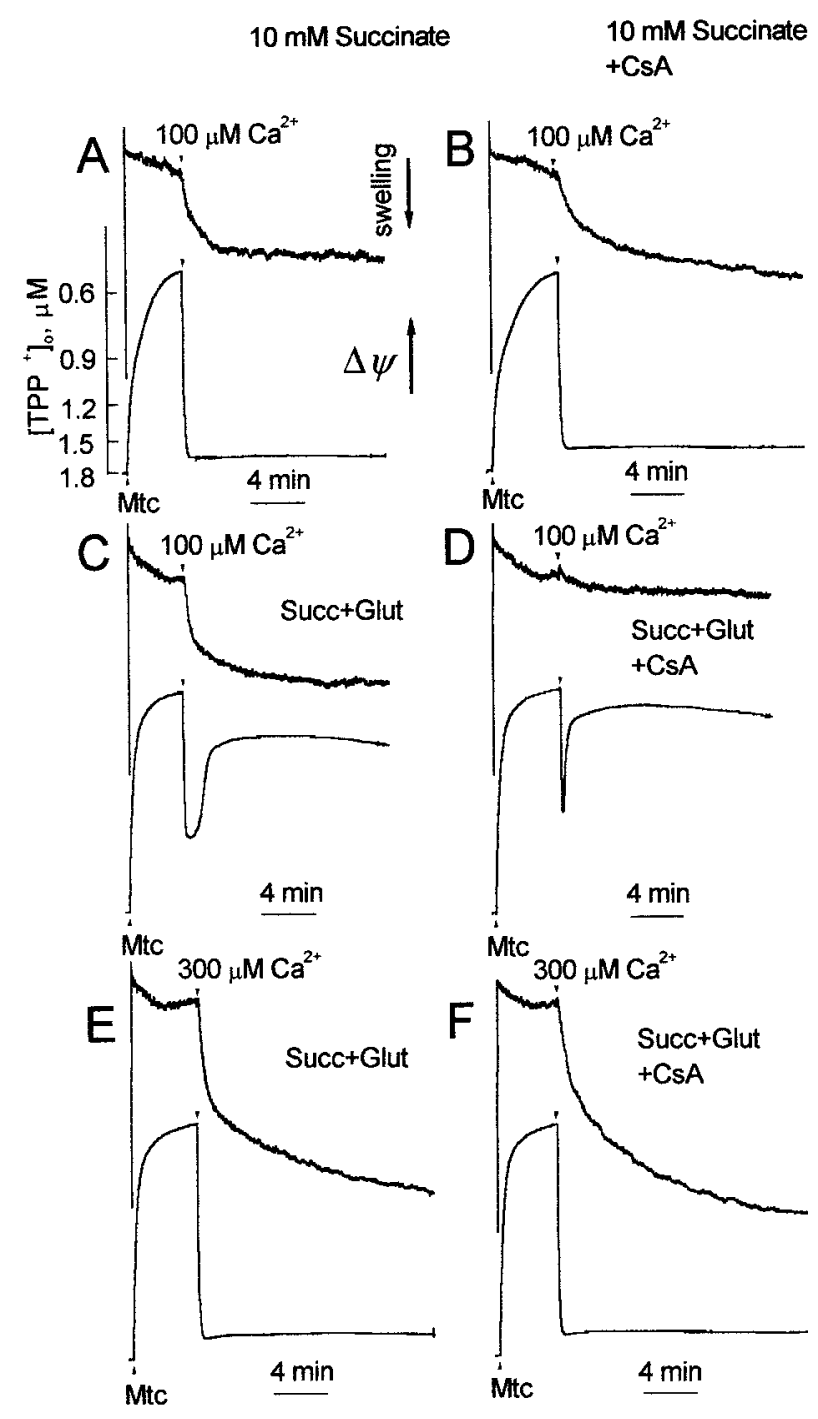

Figure 13. CsA protection against the mPT pore opening depended on depolarization. Shown are simultaneous measurements of mitochondrial swelling $\left(\mathrm{A}_{660}\right.$, top line $)$ and $\Delta \psi\left(\left[\mathrm{TPP}^{+}\right]_{\mathrm{o}}\right.$, bottom line $)$. Mitochondria were incubated in the presence of either $10 \mathrm{~mm}$ succinate $(A, B)$ or $3 \mathrm{~mm}$ succinate plus $3 \mathrm{~mm}$ glutamate $(C-F)$. Mitochondria were challenged with either $100 \mu \mathrm{M}(A-D)$ or $300 \mu \mathrm{M}(E, F) \mathrm{Ca}^{2+}$ pulses. In $B, D$, and $F, 1 \mu \mathrm{M}$ CsA was added to the medium before mitochondria. Scale bar in $A$ applies to the entire figure.

FCCP pretreatment, in the absence of $\mathrm{Mg}^{2+}$, or with excessive $\mathrm{Ca}^{2+}-\mathrm{a}$ deep sustained depolarization produced by different mechanisms correlated with the lack of CsA protection.

Closure of the high permeability state of the $\mathrm{mPT}$ pore by CsA was also dependent on the potential maintained by mitochondria. PEG addition, after $\mathrm{Ca}^{2+}$-induced mitochondrial swelling had reached a steady state, caused mitochondrial shrinkage (Fig. 15A). Under conditions in which $\mathrm{TPP}^{+}$electrode measurements indicated that mitochondria retained some potential, CsA addition before PEG prevented the shrinkage, indicating that CsA closed the mPT pore and prevented mannitol-sucrose efflux (Fig. 15B; Haworth and Hunter, 1979). When a small amount of FCCP was added for the same $\mathrm{Ca}^{2+}$ challenge or when the $\mathrm{Ca}^{2+}$ challenge was increased, mitochondrial depolarization and swelling in response to $\mathrm{Ca}^{2+}$ were exacerbated, and CsA before PEG was unable to prevent PEG-induced shrinkage (Fig. $15 C-F$ ). Thus CsA prevention of the $\mathrm{mPT}$ opening and closure of the open pore appeared to be associated with mitochondrial polarization, comparable to the limitation observed on effectiveness of CsA on the low permeability pathway. 
$\underline{\text { Succ+Glut }}$

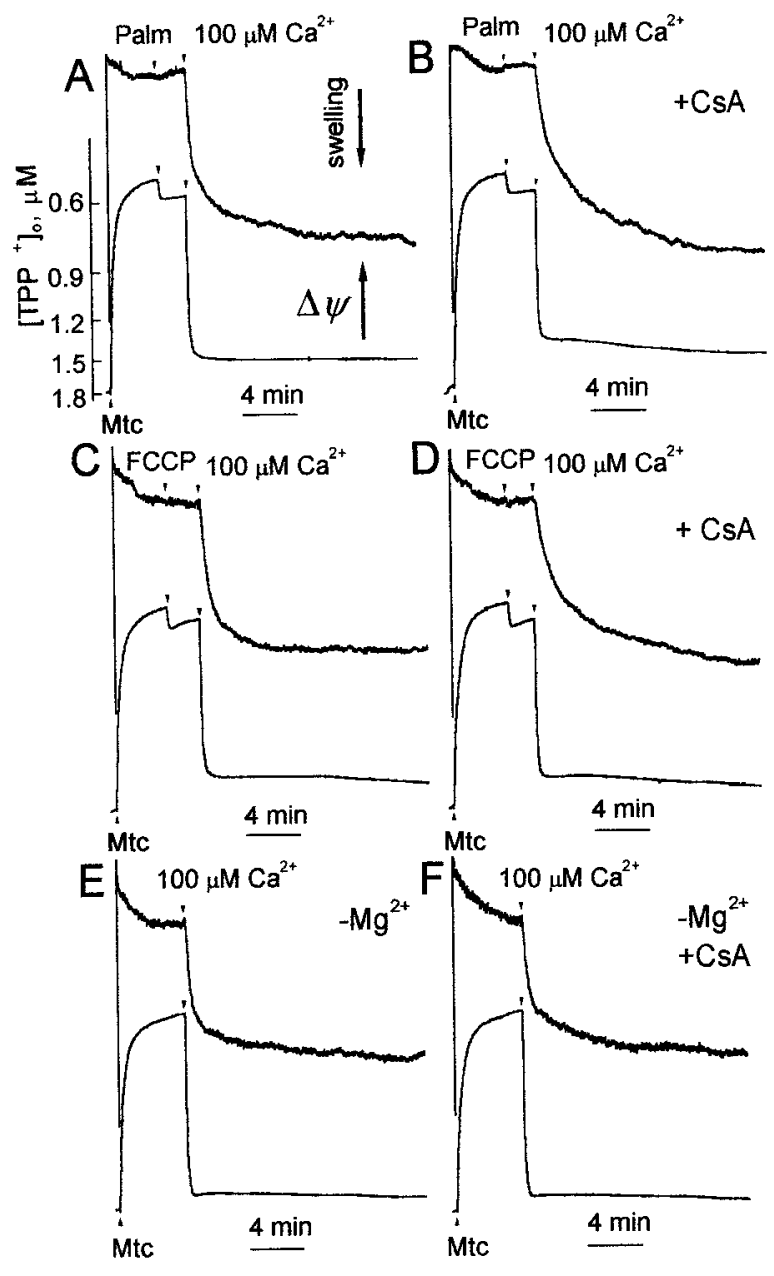

Figure 14. Treatments potentiating mitochondrial depolarization prevented CsA inhibition of $\mathrm{mPT}$ induction. Shown is the simultaneous measurement of $\mathrm{TPP}^{+}$distribution and light scattering in response to $100 \mu \mathrm{M}$ $\mathrm{Ca}^{2+}$ in the presence of $3 \mathrm{~mm}$ succinate plus $3 \mathrm{~mm}$ glutamate, conditions in which CsA prevented mitochondrial swelling and helped to maintain $\Delta \psi$ (see Fig. $8 C, D$ ). In $A$ and $B$ the mitochondria were treated with $3.3 \mu \mathrm{M}$ palmitate; in $C$ and $D$ the mitochondria were treated with 16.7 nM FCCP. In $E$ and $F, \mathrm{Mg}^{2+}$ was omitted from the medium. In $B, D$, and $F, 1 \mu \mathrm{M} C \mathrm{Cs}$ was added to the medium before mitochondria. Scale bar in $A$ applies to all parts of the figure.

\section{DISCUSSION}

\section{Antagonism of the $\mathrm{mPT}$}

In brain mitochondria ADP plus oligomycin was consistently the most reliable antagonist of $\mathrm{Ca}^{2+}$-activated mitochondrial permeabilities, comparable to liver (Haworth and Hunter, 1980). Mitochondrial swelling was both prevented and terminated by this combination. ADP plus oligomycin also inhibited PEG-induced mitochondrial shrinkage (our unpublished observations), consistent with their ability both to prevent induction and to promote closure of the $\mathrm{Ca}^{2+}$-activated low permeability state of the mPT pore (Brustovetsky and Dubinsky, 2000).

\section{Mechanisms mediating the modulation of CsA-induced inhibition}

In contrast to ADP, the ability of CsA to prevent the induction of and to close the $\mathrm{Ca}^{2+}$-activated high and low permeability states appeared to correlate with the degree of steady-state mitochondrial depolarization. Inhibition of the $\mathrm{mPT}$ pore by $\mathrm{CsA}$ was modulated by substrate environment, by FFA, by external $\mathrm{Mg}^{2+}$, by the amount of added $\mathrm{Ca}^{2+}$, or simply by a minor degree of uncoupling with FCCP or FFA. Each of these modulators in combination with
Succ+Glut

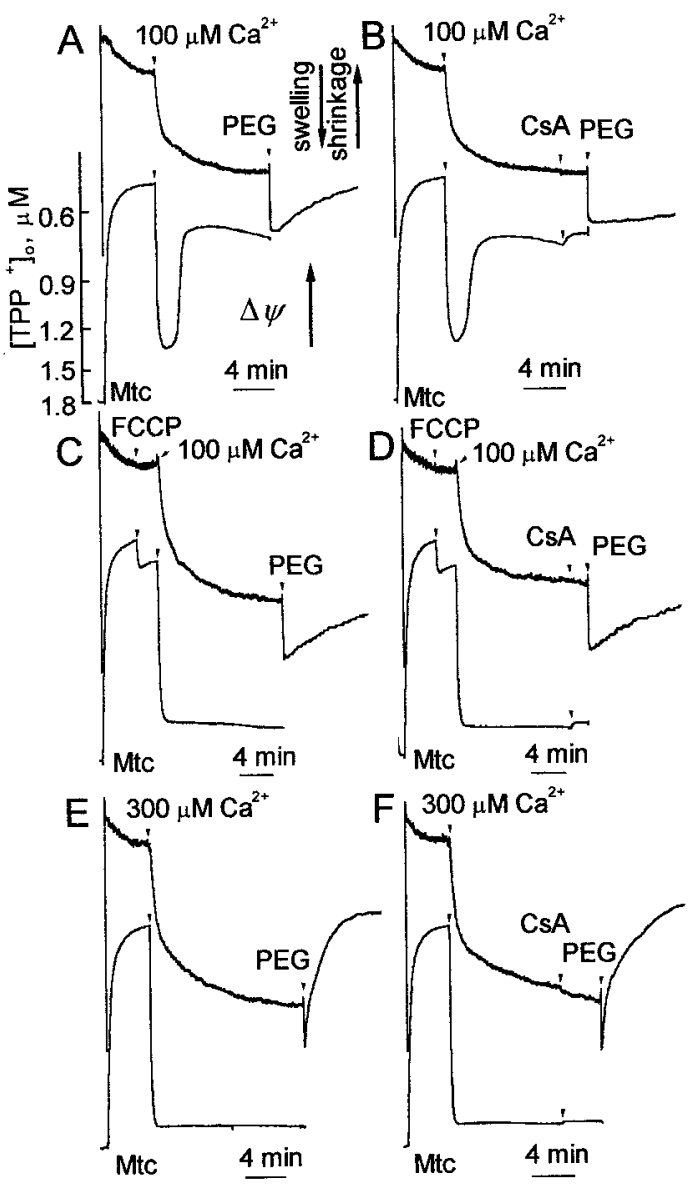

Figure 15. CsA closed the mPT pore, preventing PEG-induced shrinkage only when the mitochondria retained some potential. Shown is the simultaneous measurement of $\mathrm{TPP}^{+}$distribution and light scattering in purified mitochondria in response to $100 \mu \mathrm{M} \mathrm{Ca}{ }^{2+}$ in the presence of $3 \mathrm{mM}$ succinate plus $3 \mathrm{~mm}$ glutamate and $0.5 \mathrm{~mm} \mathrm{Mg}{ }^{2+}$. A, After $\mathrm{Ca}^{2+}$-induced mitochondrial swelling had reached a steady state, polyethylene glycol $(P E G, 3350 \mathrm{MW})$ was added, promoting osmotic shrinkage in those mitochondria with open $\mathrm{mPT}$ pores. The initial slope of the increase in light scattering after the PEG addition is proportional to the number of open mPT pores (Haworth and Hunter, 1979). The instantaneous shift in the absorbance trace was attributable to dilution of the mitochondrial solution with the PEG solution. The $\mathrm{TPP}^{+}{ }^{+}$recording was terminated with the PEG addition because of PEG-induced artifacts. The PEG addition was performed as described in Figure 5. B. Addition of $1 \mu \mathrm{M}$ CsA before PEG prevented mitochondrial shrinkage (compare the final segment of the absorbance trace with that of $A$ ), indicating that CsA closed the mPT pore. $C, E$, An increased $\left[\mathrm{Ca}^{2+}\right]$ challenge $(E)$ or pretreatment with 10 nM FCCP $(C)$ increased mitochondrial depolarization and swelling in response to $\mathrm{Ca}^{2+}$. In these conditions $1 \mu \mathrm{M}$ CsA was ineffective in closing the $\mathrm{mPT}(D, F)$.

elevated $\mathrm{Ca}^{2+}$ could act by different mechanisms to depolarize mitochondria by themselves, to modulate $\mathrm{Ca}^{2+}$-induced $\mathrm{mPT}$ induction, or to prevent $\mathrm{CsA}$-induced $\mathrm{mPT}$ pore closure directly.

Intramitochondrial $\mathrm{Ca}^{2+}$ accumulation has been postulated to antagonize the CsA repolarization of liver mitochondria directly (Crompton and Andreeva, 1994). Thus increasing the $\mathrm{Ca}^{2+}$ load would result in both greater depolarization and less CsA inhibition, as observed here. Because of the sustained depolarization, brain mitochondria failed to accumulate $100 \mu \mathrm{M} \mathrm{Ca}^{2+}$ rapidly in $3 \mathrm{~mm}$ succinate medium (Brustovetsky and Dubinsky, 2000). The amount of $\mathrm{Ca}^{2+}$ actually accumulated in these circumstances was comparable to that accumulated after a $50 \mu \mathrm{M} \mathrm{Ca}^{2+}$ challenge in which depolarization was not so severe and CsA was able to repolarize mitochondria (our unpublished results). Thus other factors must be influencing CsA inhibition in addition to the $\mathrm{Ca}^{2+}$ load.

Intramitochondrial $\mathrm{Ca}^{2+}$ could activate mitochondrial $\mathrm{PLA}_{2}$ 
(De Winter et al., 1984), leading to excessive accumulation of lysophospholipids and FFA known to influence the mPT pore complex (Wieckowski and Wojtczak, 1998). Alternatively, $\mathrm{Ca}^{2+}$ could interact with acidic phospholipids, e.g., the cardiolipin tightly bound to the adenine nucleotide transporter (ANT; Beyer and Klingenberg, 1985). From this position $\mathrm{Ca}^{2+}$ would prevent CsA from removing ANT-bound cyclophilin, allowing the ANT to maintain the $\mathrm{mPT}$ in an open state (Halestrap and Davidson, 1990). $\mathrm{Mg}^{2+}$ could potentiate CsA inhibition by binding to the cytoplasmic face of the inner membrane, inhibiting $\mathrm{mPT}$ induction (Bernardi et al., 1993). $\mathrm{Mg}^{2+}$ suppresses $\mathrm{Ca}^{2+}$-activated mitochondrial PLA 2 (Waite et al., 1969), indirectly preventing FFA accumulation. Additionally, $\mathrm{Mg}^{2+}$ can bind FFA directly (Shinohara et al., 1995). Thus the mechanisms of $\mathrm{Ca}^{2+}$ antagonism and $\mathrm{Mg}^{2+}$ potentiation of CsA inhibition may be interrelated, because both influence FFA concentration.

FFA may influence CsA inhibition via modulation of surface potential (Bernardi et al., 1994). Although the ionized carboxylic groups of FFA can modulate surface potential (Wojtczak and Schonfeld, 1993), the FCCP anion has a delocalized charge, is distributed readily within the mitochondrial membrane, and is unlikely to alter surface potential (McLaughlin and Dilger, 1980). Thus because low doses of palmitate and FCCP both acted similarly to prevent CsA inhibition, it is unlikely that either acted via a mechanism involving surface potential modulation. In addition, FFA and FCCP can act as uncouplers, potentially providing an additional pathway for decreasing mitochondrial potential.

\section{Correlation between CsA inhibition and mitochondrial polarization}

Our data demonstrated that CsA-mediated protection against the activation and closure of both high and low permeability states of the $\mathrm{mPT}$ was prevented after any manipulation producing excessive mitochondrial depolarizations beyond a threshold value. Operationally, the extent of depolarization consequent to modulation of the $\mathrm{mPT}$ by changing cytosolic $\mathrm{Ca}^{2+}, \mathrm{Mg}^{2+}, \mathrm{ADP}$, or fatty acid levels appeared to determine the probability that CsA will inhibit the depolarization and/or swelling associated with the $\mathrm{mPT}$ effectively. Any treatment likely to convert the low permeability into the high permeability pathway also would increase the probability that CsA would become ineffective by virtue of the associated increases in depolarization. The existence of any direct voltage dependence to CsA-induced $\mathrm{mPT}$ pore antagonism, although an intriguing possibility, remains to be determined. $\Delta \psi$ may influence both the structure and function of many mitochondrial membrane proteins. With depolarization the $\mathrm{Ca}^{2+}$ uniporter loses its ability to transport $\mathrm{Ca}^{2+}$ even in the presence of a significant $\mathrm{Ca}^{2+}$ gradient (Kapus et al., 1991). Also, the sensitivity of the $\mathrm{Ca}^{2+}$ uniporter to ruthenium red decreases 10 -fold when mitochondria depolarize (Broekemeier et al., 1994). The high permeability mPT state may involve the ANT. High $\Delta \psi$ enhances ADP binding to the ANT, favoring $\mathrm{mPT}$ closure (Halestrap et al., 1997). Although depolarization did not alter cyclophilin binding to mitochondrial membranes (Connern and Halestrap, 1996), a possible voltage dependence of CsA-cyclophilin interactions has not been explored.

Transient opening of the mPT pore may characterize its normal mode of behavior (Crompton, 1999). Between openings the increased proton pumping activity of the respiratory chain may compensate for a drop in $\Delta \psi$. When openings occur at a low frequency, only a fraction of mitochondria may have open pores at any point in time, and the apparent $\Delta \psi$ in the whole population may be maintained (Crompton, 1999). Nevertheless, mannitol and sucrose gradually enter mitochondria with flickering pores, inducing swelling. This could explain the swelling that is accompanied by retention of $\Delta \psi$ in our experiments with $100 \mu \mathrm{M} \mathrm{Ca}^{2+}$ (see Figs. $13,15)$.

\section{CsA protection against excitotoxicity}

The failure of CsA to protect hippocampal neurons over a wide range of glutamate doses may be explained by the limited condi- tions under which $\mathrm{CsA}$ inhibits $\mathrm{Ca}^{2+}$-activated permeabilities in isolated mitochondria. Because metabolic impairments, $\mathrm{Ca}^{2+}$, $\mathrm{Mg}^{2+}$, and FFA would be expected to act endogenously within neurons, the inability of $\mathrm{CsA}$ to prevent a $\mathrm{mPT}$ might reflect varying levels of these modulations and not the absence of a mPT. At low glutamate concentrations the $\mathrm{Ca}^{2+}$ influx into neurons might not be sufficient to activate the $\mathrm{mPT}$ despite partial depolarization of mitochondria. Cell death in these circumstances may be attributable to some other glutamate-initiated process but would not be CsA sensitive. Midrange glutamate concentrations may increase $\left[\mathrm{Ca}^{2+}\right]_{\mathrm{i}}$ sufficiently to induce a CsA-sensitive mPT. Low affinity $\mathrm{Ca}^{2+}$ dye measurements indicate 300-500 $\mu \mathrm{M}$ NMDA or glutamate increased $\left[\mathrm{Ca}^{2+}\right]_{\mathrm{i}}$ to $12-16 \mu \mathrm{M}$ (Hyrc et al., 1997; Stout and Reynolds, 1999; Brustovetsky and Dubinsky, 2000). Because increasing glutamate concentrations produce increased elevations of $\left[\mathrm{Ca}^{2+}\right]_{\mathrm{i}}$ (Rajdev and Reynolds, 1994), cytosolic calcium levels may approach those that are used to induce the $\mathrm{mPT}$ in isolated mitochondria. Actual calcium concentrations may not be so critical as the portion of the calcium load sensed by individual mitochondria (Pivovarova et al., 1999). At the highest glutamate concentrations, massive $\mathrm{Ca}^{2+}$ influx into neurons would be associated with the greatest mitochondrial depolarizations (Vergun et al., 1999; Brustovetsky and Dubinsky, 2000). Under these conditions CsA may be unable either to prevent $\mathrm{mPT}$ induction or to close the open mPT. This may explain the observations that CsA ameliorates mitochondrial depolarization in only $\sim 30 \%$ of cultured neurons (White and Reynolds, 1996; Vergun et al., 1999). In vivo, at risk neurons in an ischemic penumbral area may be experiencing milder mitochondrial depolarizations and therefore may be subject to CsA inhibition. Thus the range of glutamate concentrations and conditions producing CsA-sensitive toxicity may be narrow, despite mPT activation during excitotoxic stimulation. Alternatively, multiple neurotoxic pathways may be activated by glutamate, and antagonizing one with CsA only permits another to become the principal cause of death. Given the limited effectiveness of CsA mPT inhibition in brain mitochondria, the absence of CsA protection may not be conclusive evidence for a lack of $\mathrm{mPT}$ involvement in degenerative processes.

\section{REFERENCES}

Al-Nasser I, Crompton M (1986) The reversible $\mathrm{Ca}^{2+}$-induced permeabilization of rat liver mitochondria. Biochem J 239:19-29.

Andreyev A, Fiskum G (1999) Calcium-induced release of mitochondrial cytochrome $c$ by different mechanisms selective for brain versus liver. Cell Death Differ 6:825-832.

Andreyev AY, Fahy B, Fiskum G (1998) Cytochrome $c$ release from brain mitochondria is independent of the mitochondrial permeability transition. FEBS Lett 439:373-376.

Ankarcrona M, Dypbukt JM, Orrenius S, Nicotera P (1996) Calcineurin and mitochondrial function in glutamate-induced neuronal cell death. FEBS Lett 394:321-324.

Bernardi P, Vassanelli S, Veronese P, Colonna R, Szabo I, Zoratti M (1992) Modulation of the mitochondrial permeability transition pore: effect of protons and divalent cations. J Biol Chem 267:2934-2939.

Bernardi P, Veronese P, Petronilli V (1993) Modulation of the mitochondrial cyclosporin A-sensitive permeability transition pore. I. Evidence for two separate $\mathrm{Me}^{2+}$ binding sites with opposing effects on the pore open probability. J Biol Chem 268:1005-1010.

Bernardi P, Broekemeier KM, Pfeiffer DR (1994) Recent progress on regulation of the mitochondrial permeability transition pore, a cyclosporin-sensitive pore in the inner mitochondrial membrane. J Bioenerg Biomembr 26:509-517.

Beyer K, Klingenberg M (1985) ADP/ATP carrier protein from beef heart mitochondria has high amounts of tightly bound cardiolipin, as revealed by ${ }^{31} \mathrm{P}$ nuclear magnetic resonance. Biochemistry 24:3821-3826.

Bjorntorp P, Ells HA, Bradford RH (1964) Albumin antagonism of fatty acid effect on oxidation and phosphorylation reactions in rat liver mitochondria. J Biol Chem 239:339-344.

Blaustein MP (1975) Effects of potassium, veratridine, and scorpion venom on calcium accumulation and transmitter release by nerve terminals in vitro. J Physiol (Lond) 247:617-655.

Bradford MM (1976) A rapid and sensitive method for the quantitation of microgram quantities of protein utilizing the principle of protein-dye binding. Anal Biochem 72:248-254.

Broekemeier KM, Pfeiffer DR (1995) Inhibition of the mitochondrial permeability transition by cyclosporin A during long time frame experiments-relationship between pore opening and the activity of mitochondrial phospholipases. Biochemistry 34:16440-16449. 
Broekemeier KM, Schmid PC, Schmid HHO, Pfeiffer DR (1985) Effect of phospholipase $\mathrm{A}_{2}$ inhibitors on ruthenium red-induced $\mathrm{Ca}^{2+}$ release from mitochondria. J Biol Chem 260:105-113.

Broekemeier KM, Dempsey ME, Pfeiffer DR (1989) Cyclosporin A is a potent inhibitor of the inner membrane permeability transition in liver mitochondria. J Biol Chem 264:7826-7830.

Broekemeier KM, Krebsbach RJ, Pfeiffer DR (1994) Inhibition of the mitochondrial $\mathrm{Ca}^{2+}$ uniporter by pure and impure ruthenium red. Mol Cell Biochem 139:33-40.

Broekemeier KM, Klocek CK, Pfeiffer DR (1998) Proton selective substate of the mitochondrial permeability transition pore-regulation by the redox state of the electron transport chain. Biochemistry 37:13059-13065.

Brustovetsky N, Dubinsky JM (2000) Dual responses of CNS mitochondria to elevated calcium. J Neurosci 20:103-113.

Connern CP, Halestrap AP (1996) Chaotropic agents and increased matrix volume enhance binding of mitochondrial cyclophilin to the inner mitochondrial membrane and sensitize the mitochondrial permeability transition to $\left[\mathrm{Ca}^{2+}\right]$. Biochemistry 35:8172-8180.

Crompton M (1999) The mitochondrial permeability transition pore and its role in cell death. Biochem J 341:233-249.

Crompton M, Andreeva L (1994) On the interactions of $\mathrm{Ca}^{2+}$ and cyclosporin A with a mitochondrial inner membrane pore: a study using cobaltammine complex inhibitors of the $\mathrm{Ca}^{2+}$ uniporter. Biochem $\mathrm{J}$ 302:181-185.

Crompton M, Ellinger H, Costi A (1988) Inhibition by cyclosporin A of a $\mathrm{Ca}^{2+}$-dependent pore in heart mitochondria activated by inorganic phosphate and oxidative stress. Biochem J 255:357-360.

Dawson TM, Steiner JP, Dawson VL, Dinerman JL, Uhl GR, Snyder SH (1993) Immunosuppressant FK-506 enhances phosphorylation of nitric oxide synthase and protects against glutamate neurotoxicity. Proc Nat Acad Sci USA 90:9808-9812.

De Winter TM, Korpancova J, Van den Bosch H (1984) Regulatory aspects of rat liver mitochondrial phospholipase $\mathrm{A}_{2}$ : effect of calcium ions and calmodulin. Arch Biochem Biophys 234:243-252.

Dubinsky JM (1993) Intracellular calcium levels during the period of delayed excitotoxicity. J Neurosci 13:623-631.

Dubinsky JM, Levi Y (1998) Calcium-induced activation of the mitochondrial permeability transition in hippocampal neurons. J Neurosci Res 53:728-741.

Dubinsky JM, Brustovetsky N, Pinelis V, Kristal BS, Herman C, Li X (1999) The mitochondrial permeability transition: the brain's point of view. In: Mitochondria and cell death (Brown GC, Nicholls DG, Cooper CE, eds), pp 75-84. Princeton, NJ: Princeton UP.

Folbergrova J, Li PA, Uchino H, Smith ML, Siesjo BK (1997) Changes in the bioenergetic state of rat hippocampus during $2.5 \mathrm{~min}$ of ischemia, and prevention of cell damage by cyclosporin A in hyperglycemic subjects. Exp Brain Res 114:44-50.

Fournier N, Ducet G, Crevat A (1987) Action of cyclosporine on mitochondrial calcium fluxes. J Bioenerg Biomembr 19:297-303.

Friberg H, Ferrand-Drake M, Bengtsson F, Halestrap AP, Wieloch T (1998) Cyclosporin A, but not FK 506, protects mitochondria and neurons against hypoglycemic damage and implicates the mitochondrial permeability transition in cell death. J Neurosci 18:5151-5159.

Garlid KD (1996) Cation transport in mitochondria-the potassium cycle. Biochim Biophys Acta 1275:123-126.

Griffiths EJ, Halestrap AP (1995) Mitochondrial nonspecific pores remain closed during cardiac ischemia, but open upon reperfusion. Biochem J 307:93-98.

Halestrap AP, Davidson AM (1990) Inhibition of $\mathrm{Ca}^{2+}$-induced largeamplitude swelling of liver and heart mitochondria by cyclosporin is probably caused by the inhibitor binding to mitochondrial-matrix peptidyl-prolyl cis-trans isomerase and preventing it interacting with the adenine nucleotide translocase. Biochem J 268:153-160.

Halestrap AP, Woodfield KY, Connern CP (1997) Oxidative stress, thiol reagents, and membrane potential modulate the mitochondrial permeability transition by affecting nucleotide binding to the adenine nucleotide translocase. J Biol Chem 272:3346-3354.

Haworth RA, Hunter DR (1979) The $\mathrm{Ca}^{2+}$-induced membrane transition in mitochondria. II. Nature of the $\mathrm{Ca}^{2+}$ trigger site. Arch Biochem Biophys 195:460-467.

Haworth RA, Hunter DR (1980) Allosteric inhibition of the $\mathrm{Ca}^{2+}$ activated hydrophilic channel of the mitochondrial inner membrane by nucleotides. J Membr Biol 54:231-236.

Hunter DR, Haworth RA (1979a) The $\mathrm{Ca}^{2+}$-induced membrane transition in mitochondria. I. The protective mechanisms. Arch Biochem Biophys 195:453-459.

Hunter DR, Haworth RA (1979b) The $\mathrm{Ca}^{2+}$-induced membrane transition in mitochondria. II. Nature of the $\mathrm{Ca}^{2+}$ trigger site. Arch Biochem Biophys 195:460-467.

Hunter DR, Haworth RA (1979c) The $\mathrm{Ca}^{2+}$-induced membrane transition in mitochondria. III. Transitional $\mathrm{Ca}^{2+}$ release. Arch Biochem Biophys 195:468-477.

Hyrc K, Handran SD, Rothman SM, Goldberg MP (1997) Ionized intracellular calcium concentration predicts excitotoxic neuronal death: observations with low-affinity fluorescent calcium indicators. J Neurosci 17:6669-6677.

Kamo N, Muratsugu M, Hongoh R, Kobatake Y (1979) Membrane po- tential of mitochondria measured with electrode sensitive to tetraphenylphosphonium and relationship between proton electrochemical potential and phosphorylation potential in steady state. J Membr Biol 49:105-121.

Kapus A, Szaszi K, Kaldi K, Ligeti E, Fonyo A (1991) Is the $\mathrm{Ca}^{2+}$ uniporter a voltage-modulated transport pathway? FEBS Lett 282:61-64.

Kristal BS, Dubinsky JM (1997) Mitochondrial permeability transition in the central nervous system: induction by calcium-cycling dependent and independent pathways. J Neurochem 69:524-538.

Li PA, Uchino H, Elmer E, Siesjo BK (1997) Amelioration by cyclosporin A of brain damage following 5 or $10 \mathrm{~min}$ of ischemia in rats subjected to preischemic hyperglycemia. Brain Res 753:133-140.

Litsky ML, Pfeiffer DR (1997) Regulation of the mitochondrial $\mathrm{Ca}^{2+}$ uniporter by external adenine nucleotides: the uniporter behaves like a gated channel which is regulated by nucleotides and divalent cations. Biochemistry 36:7071-7080.

McDonald JW, Goldberg MP, Gwag BJ, Chi SI, Choi DW (1996) Cyclosporine induces neuronal apoptosis and selective oligodendrocyte death in cortical cultures Ann Neurol 40:750-758.

McDonald JW, Behrens MI, Chung C, Bhattacharyya T, Choi DW (1997) Susceptibility to apoptosis is enhanced in immature cortical neurons. Brain Res 759:228-232.

McLaughlin SGA, Dilger JP (1980) Transport of protons across membranes by weak acids. Physiol Rev 60:825-863.

Nicolli A, Basso E, Petronilli V, Wenger RM, Bernardi P (1996) Interactions of cyclophilin with the mitochondrial inner membrane and regulation of the permeability transition pore and cyclosporin A-sensitive channel. J Biol Chem 271:2185-2192.

Nieminen AL, Saylor AK, Tesfai SA, Herman B, Lemasters JJ (1995) Contribution of the mitochondrial permeability transition to lethal injury after exposure of hepatocytes to $t$-butylhydroperoxide. Biochem J 307:99-106.

Nieminen AL, Petrie TG, Lemasters JJ, Selman WR (1996) Cyclosporin A delays mitochondrial depolarization induced by $N$-methyl-D-aspartate in cortical neurons: evidence of the mitochondrial permeability transition. Neuroscience 75:993-997.

Novgorodov SA, Gudz TI, Milgrom YM, Brierly GP (1992) The permeability transition in heart mitochondria is regulated synergistically by ADP and cyclosporin A. J Biol Chem 267:16274-16282.

Novgorodov SA, Gudz TI, Brierly GP, Pfeiffer DR (1994) Magnesium ion modulates the sensitivity of the mitochondrial permeability transition pore to cyclosporin A and ADP. Arch Biochem Biophys 311:219-228.

Pfeiffer DR, Kauffman RF, Lardy HA (1978) Effects of $N$-ethylmaleimide on the limited uptake of $\mathrm{Ca}^{2+}, \mathrm{Mn}^{2+}$, and $\mathrm{Sr}^{2+}$ by rat liver mitochondria. J Biol Chem 253:4165-4171.

Pfeiffer DR, Gudz TI, Novgorodov SA, Erdahl WL (1995) The peptide mastoparan is a potent facilitator of the mitochondrial permeability transition. J Biol Chem 270:4923-4932.

Pivovarova NB, Hongpaisan J, Andrews SB, Friel DD (1999) Depolarization-induced mitochondrial $\mathrm{Ca}$ accumulation in sympathetic neurons: spatial and temporal characteristics. J Neurosci 19:6372-6384.

Rajdev S, Reynolds IJ (1994) Glutamate-induced intracellular calcium changes and neurotoxicity in cortical neurons in vitro: effect of chemical ischemia. Neuroscience 62:667-679.

Riley WW, Pfeiffer DR (1985) Relationships between $\mathrm{Ca}^{2+}$ release, $\mathrm{Ca}^{2+}$ cycling, and $\mathrm{Ca}^{2+}$-mediated permeability changes in mitochondria. J Biol Chem 260:12416-12425.

Schinder AF, Olson EC, Spitzer NC, Montal M (1996) Mitochondrial dysfunction is a primary event in glutamate neurotoxicity. J Neurosci 16:6125-6133.

Shinohara Y, Unami A, Teshima M, Nishida H, Van Dam K, Terada H (1995) Inhibitory effect of $\mathrm{Mg}^{2+}$ on the protonophoric activity of palmitic acid. Biochim Biophys Acta 1228:229-234.

Stout AK, Reynolds IJ (1999) High-affinity calcium indicators underestimate increases in intracellular calcium concentrations associated with excitotoxic glutamate stimulations. Neuroscience 89:91-100.

Vergun O, Keelan J, Khodorov BI, Duchen MR (1999) Glutamateinduced mitochondrial depolarisation and perturbation of calcium homeostasis in cultured rat hippocampal neurones. J Physiol (Lond) 519:451-466

Waite M, Scherphof GL, Boshouwers FMG, Van Deenen LLM (1969) Differentiation of phospholipase A in mitochondria and lysosomes of rat liver. J Lipid Res 10:411-420.

White RJ, Reynolds IJ (1996) Mitochondrial depolarization in glutamatestimulated neurons: an early signal specific to excitotoxin exposure. J Neurosci 16:5688-5697.

Wieckowski MR, Wojtczak L (1998) Fatty acid-induced uncoupling of oxidative phosphorylation is partly due to opening of the mitochondrial permeability transition pore. FEBS Lett 423:339-342.

Wojtczak L, Schonfeld P (1993) Effect of fatty acids on energy coupling processes in mitochondria. Biochim Biophys Acta 1183:41-57.

Zamzami N, Marchetti P, Castedo M, Hirsch T, Susin SA, Masse B, Kroemer G (1996) Inhibitors of permeability transition interfere with the disruption of the mitochondrial transmembrane potential during apoptosis. FEBS Lett 384:53-57.

Zoratti M, Szabo I (1995) The mitochondrial permeability transition. Biochim Biophys Acta 1241:139-176. 